\title{
Correction to: Mathematical arterialisation of peripheral venous blood gas for obtainment of arterial blood gas values: a methodological validation study in the clinical setting
}

\author{
Mads Lumholdt ${ }^{1,2,3,5}$ - Kjeld Asbjørn Damgaard ${ }^{1}$. Erika Frischknecht Christensen ${ }^{4}([)$ \\ Peter Derek Christian Leutscher ${ }^{2,3}$ [0
}

Published online: 23 April 2019

(c) Springer Nature B.V. 2019

\section{Correction to: \\ Journal of Clinical Monitoring and Computing https://doi.org/10.1007/s10877-018-0197-1}

The corresponding author has identified a calculation mistake in the original publication of the article. The corrected value is given in this Correction.

Under the Results section, the median (range) age of the patients in the methodological study should read 76 (26-86) years instead of 56 (26-86) years.
Publisher's Note Springer Nature remains neutral with regard to jurisdictional claims in published maps and institutional affiliations.

The original article can be found online at https://doi.org/10.1007/ s10877-018-0197-1.

Mads Lumholdt m.lumholdt@rn.dk

1 Department of Anaesthesiology, North Denmark Regional Hospital, Bispensgade 37, 9800 Hjørring, Denmark

2 Centre for Clinical Research, North Denmark Regional Hospital, Bispensgade 37, 9800 Hjørring, Denmark

3 Clinical Institute, Aalborg University, Søndre Skovvej 11, 9000 Aalborg, Denmark

4 Centre for Prehospital and Emergency Research, Clinical Institute, Aalborg University, Søndre Skovvej 11, 9000 Aalborg, Denmark

5 Hals, Denmark 